\section{Imaging Microanalysis of Materials with a Finely Focused Heavy Ion Probe}

\author{
R. Levi-Setti, J. Chabala, and Y, L. Wang \\ The Enrico Fermi Institute and \\ Department of Physics \\ The University of Chicago \\ Chicago, IL 60637
}

\section{Scanning Analytical Heary Ion Microscopy at High Lateral Resolution}

Liquid metal ion sources (LMIS) in view of the quasi-point-like geometry of their emitting region and confined emission cone possess brightness $\left(\sim 10^{6} \mathrm{~A} \mathrm{~cm}^{-2} \mathrm{sr}^{-1}\right)$ which is adequate for the realization of high current density $\left(\sim 1 \mathrm{~A} \mathrm{~cm}^{-2}\right)$, finely focused $(\geqslant 20 \mathrm{~nm}$ ) probes. A $40 \mathrm{keV}$ scanning ion microprobe, which makes use of a Ga LMIS (UCHRL SIM) is currently employed in our laboratory to obtain chemical maps of materials in a variety of interdisciplinary applications [1]. The instrument is composed of a two-lens focusing column, a hightransmission secondary ion energy analyzer and transport system, and an RF quadrupole mass filter for secondary ion mass spectrometry (SIMS). In addition, two-channel electron multiplier detectors, overlooking the target region, collect secondary electrons or ions for imaging of the surface topography and material contrast of a sample.

Although a lateral resolution of $20 \mathrm{~nm}$ has been attained, sensitivity considerations favor operation at somewhat larger $(50-70 \mathrm{~nm})$ probe size. The analytical image resolution is in fact critically dependent on the statistics of the mass analyzed signal [2], which in turn is determined by the rate of material removal by sputtering from the sample surface. Such a rate is proportional to the probe current, which decreases with the square of the probe diameter for chromatic-aberration-limited probes such as those extracted from LMIS. Thus at, e.g., $20 \mathrm{~nm}$ probe diameter, only 1-2 pA of probe current are available, the erosion rate is of the order $\sim 10^{-3}$ monolayers/s and probe-size resolution can only be attained for elements of high ionization probability which will provide the highest signal statistics over an acceptable recording time $(>1$ count/pixel in a $1024 \times 1024$ pixel scan for a $512 \mathrm{~s}$ acquisition time for the UC-HRL SIM).
In view of the well known range of ionization probabilities (ion fractions) among sputtered atomic species, as well as of sputtering yields, the attainable analytical lateral resolution of finely focused probes becomes target-species dependent due to the above considerations. It also follows that for species difficult to ionize, high resolution SIMS imaging microanalysis is altogether precluded, unless by recourse to postionization techniques [3].

Two examples of applications of the UC-HRL SIM to the study of materials will be illustrated in the present context.

\section{Imaging Micro-SIMS of Aluminum-Lithium Alloys}

SIMS techniques are uniquely suited to the study of $\mathrm{Li}$ because of the intense ${ }^{7} \mathrm{Li}^{+}$signal emerging from fast ion bombardment of $\mathrm{Li}$-containing materials. The high resolution imaging capability of the UC-HRL SIM can be fully exploited in this case, as demonstrated in preliminary studies of Al-Li alloys containing up to 12.7 at. \% $\mathrm{Li}[4,5]$. In these important alloys, the ${ }^{7} \mathrm{Li}^{+}$signal is detected with a signalto-noise ratio $\approx 10^{5}$, and it is feasible to image and identify grain boundary phases and precipitates in the $<100 \mathrm{~nm}$ range of dimensions.

Samples of binary Al-Li alloys were solution treated for $\sim 10 \mathrm{mins}$ at $570^{\circ} \mathrm{C}$ and water quenched. Some of the samples were then aged to give coarse distributions of either the equilibrium $\delta$ (AlLi) phase or a combination of $\delta$ and metastable $\delta^{\prime}\left(\mathrm{Al}_{3} \mathrm{Li}\right)$. The samples were first mechanically polished and then electropolished to produce a flat surface for SIMS imaging.

A number of SIMS artifacts originating in the sample preparation process could be identified and subsequently avoided. These involve Li surface enrichment, surface oxidation and chlorine and carbon contamination. Sputter-cleaning of the samples in situ with a $2 \mathrm{kV}$ Ar ion gun was generally necessary to obtain clean and artifact-free surfaces. An example of the detection of $\delta$ plates in Al12.7 at. \% $\mathrm{Li}$ aged 100 hours at $250^{\circ} \mathrm{C}$ is shown in the ${ }^{7} \mathrm{Li}^{-}$map of figure 1 (a). The plates form in regular crystallographic orientations. $\mathrm{A}^{34} \mathrm{AlLi}^{+}$image is shown in figure $1(\mathrm{~b})$ where $\delta^{\prime}$ particles (dark inclusions) are detected, showing distinctive morphologies that include dendritic growth and mucleation on dislocations. In the latter case, the Al-10.1 at. \% Li sample was aged 4 hours at $290^{\circ} \mathrm{C}$. 


\section{Accuracy in Trace Analysis}

Toward quantification, a calibration curve has been constructed from ${ }^{7} \mathrm{Li}^{+} /{ }^{27} \mathrm{Al}^{+}$measurements performed on binary $\mathrm{Al}-\mathrm{Li}$ alloys of known $\mathrm{Li}$ concentration. A linear relation between the ${ }^{7} \mathrm{Li}^{+} /$ ${ }^{27} \mathrm{Al}^{+}$ratio and the composition of the standard was observed, as shown in figure 2.

\section{Imaging Micro-SIMS of Silicon Nitride Ceramics}

Sintered silicon nitride is an advanced ceramic often used for high-temperature applications. The sintering process requires the addition of small amounts of oxides in a nitrogen overpressure to prevent dissociation above $1700^{\circ} \mathrm{C}$. Sintering agents such as $\mathrm{MgO}, \mathrm{Y}_{2} \mathrm{O}_{3}$ and others, present in $1-10 \%$ weight concentrations, react with the silicon nitride phases and the secondary phases, which form along grain boundaries determine the mechanical properties of the ceramic.

Using the UC-HRL SIM, it has been feasible to obtain detailed mapping of the components of the interboundary phases in both yttria- and magnesiadoped silicon nitride [6]. Both fractured and polished surfaces of these ceramics can be readily analyzed in our microprobe, after coating with a thin $(\sim 5 \mathrm{~nm})$ Au layer, which is rapidly sputtered away from the field of view under investigation.

In the case of $\mathrm{Y}_{2} \mathrm{O}_{3}$-sintered silicon nitride, the dominant interboundary phase is $\mathrm{YSiO}_{2} \mathrm{~N}$, known to oxidize to $\mathrm{Y}_{2} \mathrm{Si}_{2} \mathrm{O}_{7}$. SIMS mapping of these phases can be obtained for several break-up fragments such as $\mathrm{Y}^{+}, \mathrm{O}^{-}, \mathrm{SiO}_{2}^{-}$and $\mathrm{SiN}^{-}$. In addition differential resputtering of the implanted $\mathrm{Ga}^{+}$ probe ions provides detailed descriptions of the structure of the ceramic comparable to that which can be obtained with backscattered electrons. An example of the level of detail and resolution that can be attained in the imaging microanalysis of this ceramic is shown in figure 3 . Figure $3(a)$ is a ${ }^{69} \mathrm{Ga}^{+}$ map, figure $3(\mathrm{~b})$ a ${ }^{89} \mathrm{Y}^{+}$map of the same fracture surface. The silicon nitride crystallites representing the ceramic matrix are clearly outlined in the $\mathrm{Ga}^{+}$ map, while the complementary $\mathrm{Y}^{+}$map describes the distribution of the interboundary phase.

Quantification of the composition of the interboundary phase by SIMS is complicated by the presence of matrix effects and local ion yield enhancements in the presence of bound oxygen. Methods are being developed, based on image processing techniques, to perform vector scan microanalysis of either the matrix or the interboundary phases separately. Aided by suitable standards, it is expected that quantification on a microscale may become feasible by this approach.

\section{Acknowledgments}

This research was supported by the NSF Materials Research Laboratory at the University of Chicago, the Allied Signal Engineered Materials Research Center, and the National Science Foundation under Grant No. DMR-861 2254.
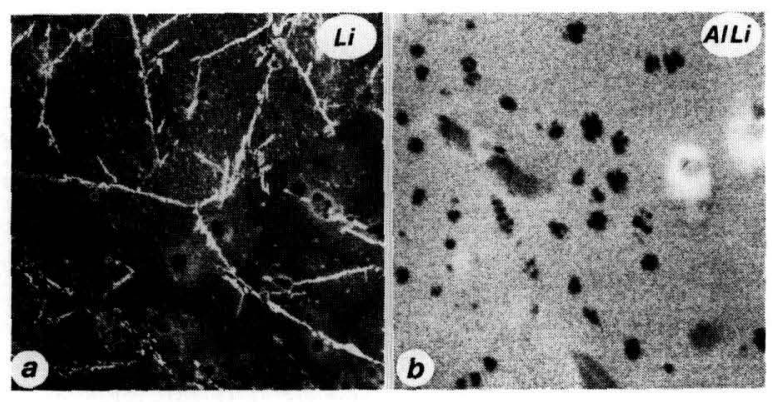

Figure 1. (a) ${ }^{7} \mathrm{Li}^{+}$SIMS image of $\delta$ plates in $\mathrm{Al}-12.7$ at. $\% \mathrm{Li}$ alloy. $80 \mu \mathrm{m}$ full scale. (b) ${ }^{34} \mathrm{AlLi}^{+}$SIMS image of dendritic $\delta$ particles in Al-10.1 at. \% Li. $10 \mu \mathrm{m}$ full scale.

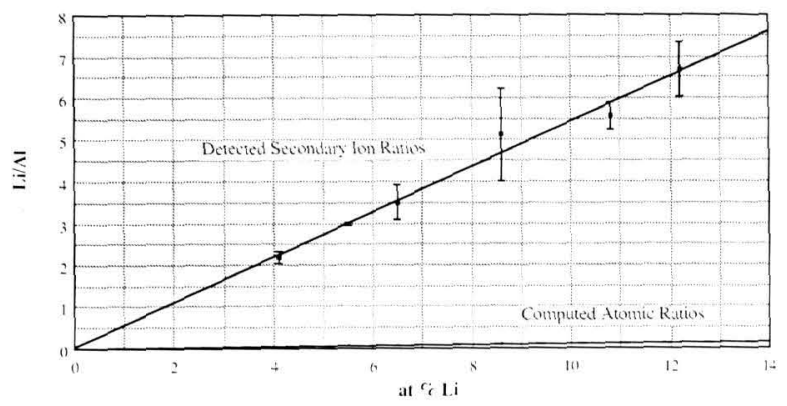

Figure 2. ${ }^{7} \mathrm{Li}^{+} /{ }^{27} \mathrm{Al}^{+}$calibration obtained for the UC-HRL SIM from homogeneous as-quenched samples of binary $\mathrm{Al}-\mathrm{Li}$ alloys.
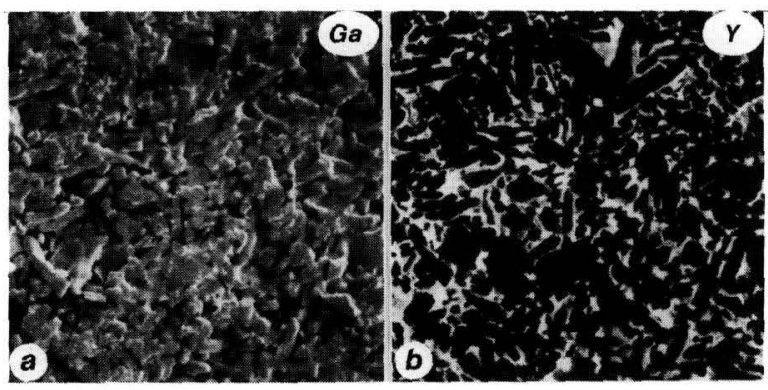

Figure 3. (a) Resputtered ${ }^{69} \mathrm{Ga}^{+}$SIMS image of fracture surface of $\mathrm{Y}_{2} \mathrm{O}_{3}$-sintered silicon nitride ceramic, $20 \mu \mathrm{m}$ full scale. (b) ${ }^{89} \mathrm{Y}^{+}$image showing distribution of interboundary phase in same area as (a). 


\section{References}

[1] Levi-Setti, R., Wang, Y. L., and Crow, G., Appl. Surf. Sci. 26, 249 (1986).

[2] Levi-Setti, R., Chabala, J., and Wang, Y. L., Scanning Micros. Suppl. 1, 13 (1987).

[3] Wang, Y. L., Levi-Setti, R., and Chabala, J., Scanning Microsc. 1 (1987).

[4] Williams, D. B., Levi-Setti, R., Chabala, J. M., and Newbury, D. E., J. Microsc. (1987) in press.

[5] Williams, D. B., Levi-Setti, R., Chabala, J. M., and Newbury, D. E., to be submitted to J. Microsc.

[6] Chabala, J. M., Levi-Setti, R., Bradley, S. A., and Karasek, K. R., Imaging Microanalysis of Silicon Nitride Ceramics with a High Resolution Scanning Ion Microprobe. Appl. Surf. Sci. (1987) in press.

\section{Synchrotron Radiation Excited Fluorescence Micro-Analysis Using a New Imaging Technique}

\section{A. Knöchel, M. Bavdaz' ${ }^{1}$ N. Gurker1, P. Ketelsen, W. Petersen, M. H. Salehi, and T. Dietrich}

Universität Hamburg

Institut für Anorganische und Angewandte Chemie

Martin-Luther-King-Platz 6

D-2000 Hamburg, FRG

\section{Introduction}

The great importance and large field of applications the $\mathrm{x}$-ray fluorescence analysis (XFA) found in the last decade are due to its extraordinary qualities. It is a very flexible method, it is nondestructive, fast and requires only a very simple sample preparation. It is not necessary to perform the analysis in vacuum, so samples containing volatile components pose no problem (e.g., biological and medical samples).

The penetration depth of $x$-rays ranges from a few $\mu \mathrm{m}$ up to several $100 \mu \mathrm{m}$ and is thus much greater than that of electrons (used to excite the sample with scanning electron microscopy). The analyzed volume of the sample thus increases and

\footnotetext{
'Technische Universität Wien, Institut für Angewandte und Technische Physik, Karlsplatz 13, A-1040 Vienna, Austria.
}

results in a high sensitivity of the method. Additionally, $x$-rays cause much less radiation damage than corpuscular beams [1].

Using synchrotron radiation as a very powerful primary $x$-ray source, the sensitivity of the method is very high and is comparably good for all elements having $Z \geqslant 18[2,3]$. Figure 1 shows the detection limits for synchrotron radiation excited $\mathrm{x}$-ray fluorescence analysis (SYXFA). A $1 \mathrm{mg} / \mathrm{cm}^{2}$ multielement sample was measured for $300 \mathrm{~s}$ using a beam diameter of $0.5 \mathrm{~mm}$. The solid line indicates the detection limits measured using a white beam, the dotted line those using a graphite monochromator adjusted to eliminate the As- $\mathrm{K} \alpha / \mathrm{Pb}-\mathrm{L} \alpha$ interference.

The main advantages of applying synchrotron light as the primary radiation source in XFA could be summarized as follows:

- The high photon flux makes filtering, monochromatizing and masking of the primary beam feasible.

- A very broad continuous white spectrum allows simultaneous multi-elemental analysis featuring very good limits of detection (absolute $\geqslant 10^{-13} \mathrm{~g}$, relative $\geqslant 0.1 \mu \mathrm{g} / \mathrm{g}$ ).

- Synchrotron radiation is linearly polarized in the storage-ring plane, thus improving the signal-to-noise ratio significantly.

- The source size is very small and the synchrotron beam is very well collimated, so a high spatial resolution is achievable (see later).

- Since the properties of synchrotron radiation are calculable, the evaluation of the measured data becomes easier and more reliable.

We are applying SYXFA to help solving different analytic problems that hardly could be approached with other methods. For example, we analyzed cosmic dust particles smaller than $10 \mu \mathrm{m}$ in diameter to find out their composition. A second example is the analysis of the printing ink on very precious documents, including the 42 -line bible by Gutenberg.

\section{X-Ray Imaging}

SYXFA becomes even more interesting if one succeeds in combining spatial resolving analysis with the high sensitivity of the method. 